\title{
Porosity Prediction from Seismic Inversion Properties over 'XLD' Field, Niger Delta
}

\author{
${ }^{1}$ Adekanle A. and ${ }^{2}$ Enikanselu P. A. \\ ${ }^{1}$ P.O. Box 2628, Somolu, Lagos. Nigeria \\ ${ }^{2}$ Department of Applied Geophysics, Federal University of Technology, P.M.B. 704, \\ Akure. Nigeria. \\ ${ }^{2}$ E-mail: pa.enikan@yahoo.com \\ Corresponding Author: +2348028422122/aadekanle@yahoo.com
}

\begin{abstract}
The study attempts to enhance the characterization of subsurface reservoirs by improving the spatial prediction of petrophysical properties through integration of petrophysical measurements and 3D seismic observations in a field in the Southern part of Nigeria. This goal is fulfilled by the use of a-priori multi-regression analysis on seismic simultaneous inversion properties, a functional relationship between measured porosity log and seismic inversion properties derived at the well location. Once derived, the relationship is applied to the inversion properties and a porosity cube is generated. Being constrained by physical properties and observations at the well, the resulting porosity estimates from inversion properties are appropriate for making reservoir management decisions. In addition, the result provides a geologically realistic spatial porosity distribution which helps to understand the subsurface reservoirs heterogeneities in the study area.
\end{abstract}

\section{INTRODUCTION}

Porosity and permeability are the most difficult properties to determine in subsurface reservoir characterization; yet usually they have the largest impact on reserves and production forecasts, and consequently on the economy of a prospect. The difficulty of estimating them comes from the fact that porosity and permeability may vary significantly over a reservoir volume, but can only be sampled at well locations, often using different technologies at different scales of observation. Solution to the aforementioned problem requires the integration of rock physics, petrophysics, and surface seismic in order to guarantee consistency of analysis and results. Elastic properties - and therefore seismic data - are mostly affected by porosity and lithology. In some cases, they may also be affected by pore fluid replacement, which is controlled by permeability. An accurate estimation of the spatial distribution of porosity and permeability is of key importance, though, because it translates into higher success rates in infill drilling, and fewer wells required for draining the reservoir.
Among the parameters necessary for the definition of a reservoir, porosity is one of the most important and at the same time the most difficult to compute. The pore volume of clastic rocks is generally made up of intergranular openings between the mineral grains. Fracture and fissure porosity is often present and sometimes may be the main factor to be considered in the evaluation of the characteristics of a clastic rock as a potential economic reservoir. In carbonate reservoirs many types of porosity may be distinguished, but, as far as reservoir evaluation is concerned, the porosity may generally be considered as the contributed effect of two distinct causes: (i) matrix porosity with pore spaces generally small and consequently small permeability; (ii) fracture, fissure, and joint porosity with large pore size and high permeability.

Quantitative evaluation of the porosity of a rock is often as difficult as it is important. The main problems arise in the presence of dispersed shale or when the reservoir rock exhibits several types of porosity. Porosity may be determined by various methods. Some of these make use of core samples; others are based on well-log data and mathematical models. Of 
particular interest are techniques of porosity estimate from transit time analyses that make use of interval velocities obtained from seismic traces. Well observations provide good vertical resolution of geologic strata, but are at sparse locations. In contrast, 3D seismic method provides dense and regular areal sampling but with considerably lower vertical resolution. The integration of 3D seismic data with petrophysical measurements at wells can significantly improve the spatial distribution of porosity. The application of seismic attributes is a widely used method to decrease the spatial uncertainty of the parameter prediction. Knowing the spatial distribution of petrophysical parameters between wells in a hydrocarbon reservoir is a very important role in predicting the most economical and optimal production possibilities by flow simulation.

During the last decades, several methods for mapping or estimating rock properties from seismic data were developed and tested with the aim of providing additional information for detailed reservoir characterization. The first deterministic inversion methods for acoustic impedance mapping were developed in the late 1970s and became to be known generally as recursive inversion (Lavergne and Willm, 1977; Lindseth, 1979). Nowadays, most of the research efforts in this field are focused in the inversion and interpretation of variations of seismic reflection amplitude with change in distance between source and receiver (amplitude vs. offset) from prestack data. However, post-stack data obtained from recorded $\mathrm{P}$-waves are still widely used because of their ready availability and low time-consuming processing. Because wells in a reservoir field are often spaced at hundreds or even thousands of meters, the ultimate goal of a seismic inversion procedure in the context of reservoir characterization is to provide models not only of acoustic impedance but also of other relevant physical properties, such as effective porosity and water saturation, for the interwell regions. Such quantitative interpretations may sometimes require the use of other seismic attributes in addition to the traditional seismic reflection amplitudes (Rijks and Jauffred, 1991; Lefeuvre et al., 1995; Russell, 2004; Sancevero et al., 2005; Soubotcheva, 2006).

Successful petrophysical parameter (porosity) prediction using seismic inversion properties is described in this paper. The seismic inversion method that is used in this work is classified as deterministic simultaneous inversion method (Russell, 1988). Although many recent papers have demonstrated some advantages of geostatistical methods over deterministic methods (Robinson, 2001), the latter, with good quality datasets, provides geologically plausible acoustic impedance and other rock properties at a much lower computational cost.

Prediction of reservoir petrophysical parameters from seismic inversion properties such as acoustic impedance traditionally have been addressed through the application of multivariate statistics and, more recently, the Neural Network (NN) methods, especially when it becomes necessary to extract nonlinear relationships between the input data and the target property (Leiphart and Hart, 2001; Hampson et al., 2001; Walls et al., 2002; Pramanik et al., 2004; Calderon, 2007). This paper uses the multiattribute analysis method to predict porosity from simultaneous inversion properties.

Location and Geology: The oilfield studied is located in the Southern part of Nigeria. The interval examined is represented by a sequence of nearshore clastics (sands and shales) overlain by marine shales, whose deposition occurred in an outer-shelf environment. The sand units exhibit lithological variation which affects porosity distribution. The main rock type of the reservoir is low acoustic impedance high porosity clastic, which generates a marker type reflection on seismic sections. In this work, we are only concentrating on a reservoir in the field. The average thickness of the reservoir is 24.4 meters (80ft), based on well data. One well was drilled in the field, and with well log data. The whole reservoir is covered by 3D seismic data. Acoustic travel time log and checkshot data are available to determine the time-depth curve in the well using synthetic seismogram.

\section{MATERIALS AND METHODS}

Porosity evaluation from seismic data is a very important tool because it permits the definition of porosity distribution even far from drilled wells, allows a better characterization of known reservoirs in their economical and technical aspects, and provides much more information than does normal seismic processing in the search for new hydrocarbon fields.

Integrating well log and seismic datasets, angle dependent simultaneous seismic inversion is carried out to estimate rock properties such as P- and Simpedances, and density. Other properties are the lambda-rho, mu-rho, the ratio of $\mathrm{P}$ - to S-wave velocities $(\mathrm{Vp} / \mathrm{Vs})$, and Poisson's ratio. The sensitivity of each seismic inversion property to porosity is investigated. In the sensitivity analysis, each 
inversion property (in log form) is correlated to porosity well log data, and cross correlation measured, to determine the most suitable property for porosity prediction. The lambda-rho proved to be the most important single property with cross correlation of about $40 \%$, the P- and S-impedances data are less sensitive and the mu-rho data did not yield additional information than that already in the lambda-rho data and therefore redundant for a single regression based prediction. Therefore, no single property is sensitive enough to provide a good prediction of porosity. However, all the inversion properties are simultaneously used as inputs to train multi-attribute regression analysis. The application of the best multi-attribute regression yields a very good estimate of 3D porosity distribution for the study area.

\section{RESULTS AND DISCUSSION}

None of the inversion properties is sensitive enough to predict porosity. Hence all the inversion properties were integrated as input to train a multi-attribute regression analysis. Figure 1 shows the properties used.

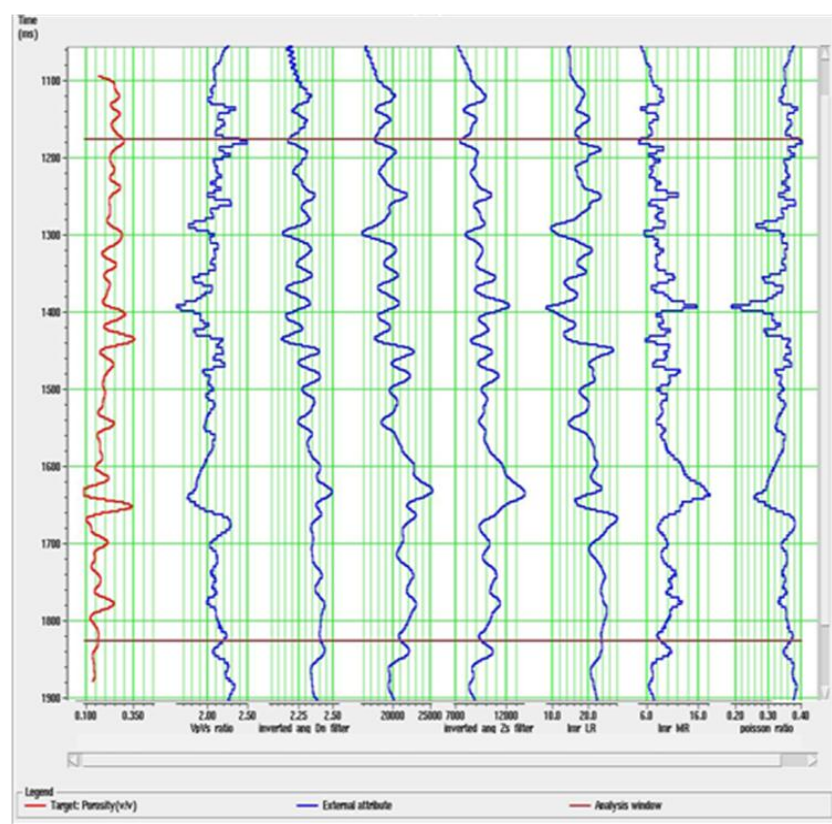

Figure 1: Inversion properties used to train multi-regression analysis

A very good cross correlation between the predicted and actual porosity is achieved using all the properties together to derive a multi-regression (Figure 2). The regression is applied to the inversion properties to estimate porosity at the training well (Figure 3).

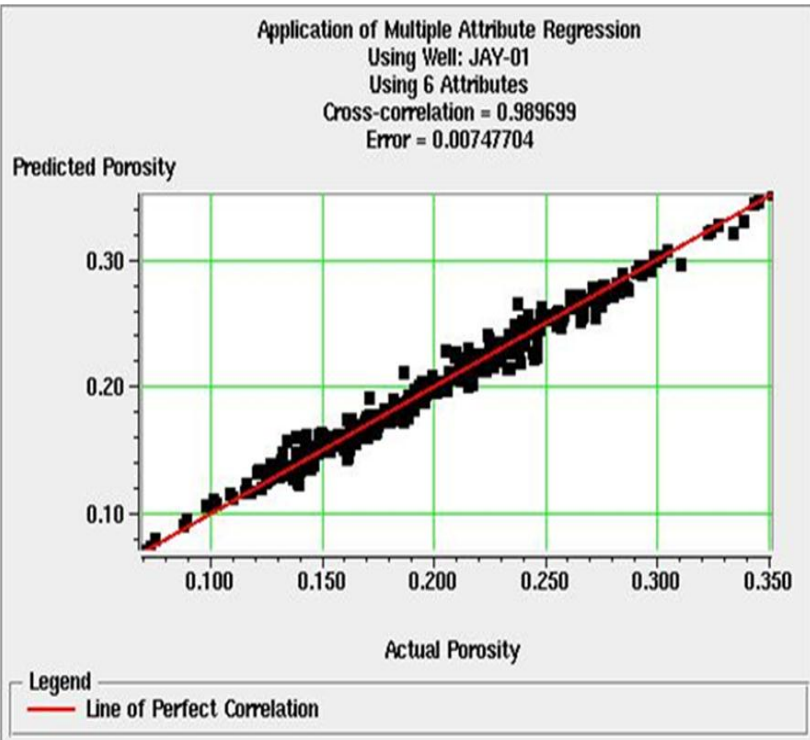

Figure 2: Cross correlation of predicted porosity and actual porosity at training well

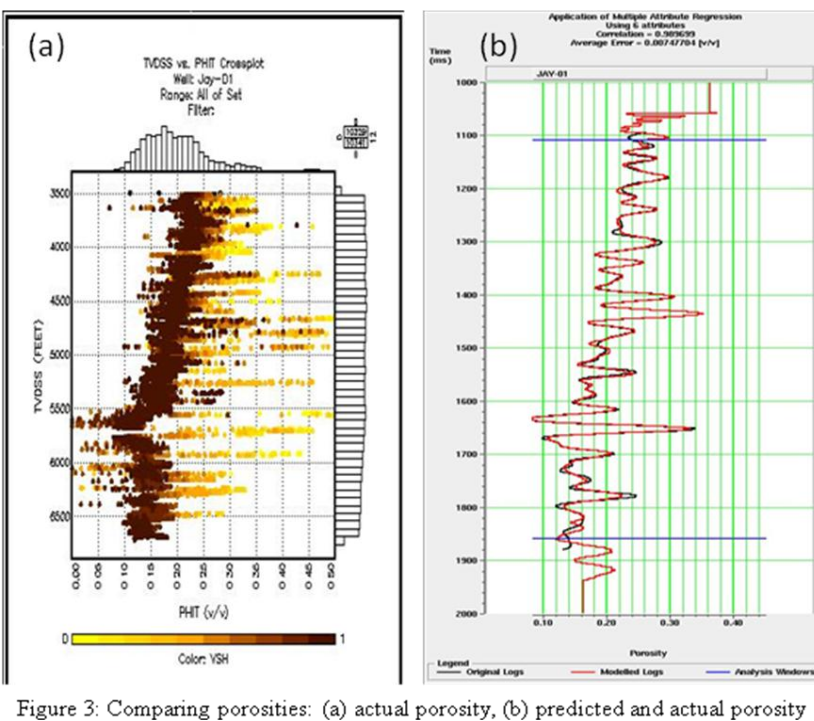

Applying the multi-regression weights to the inversion properties, a 3D porosity volume is estimated (Figure 4). The figure maps the porosity distribution of a key reservoir in the study area. The estimated porosity shows some degree of heterogeneity that exists in the reservoir, which is useful when planning development of infill wells. The heterogeneity is more visible when looking at the reservoir in map view, Figure 5. 


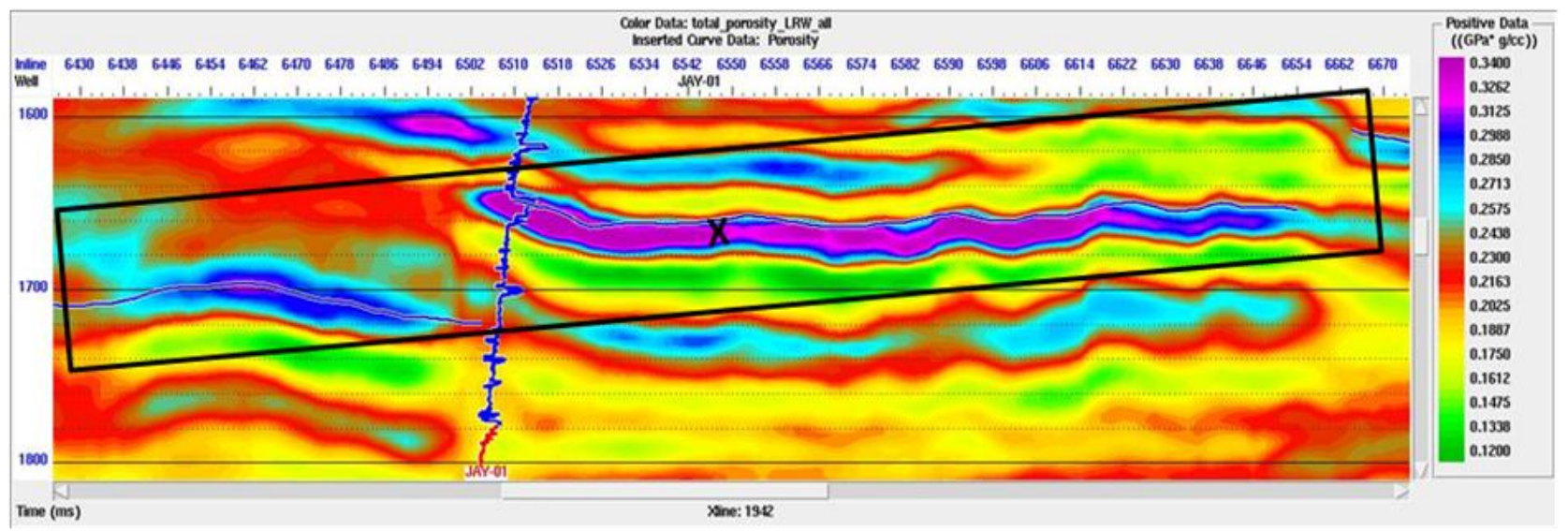

Figure 4: Porosity volume showing a reservoir ' $\mathrm{X}$ ' in the study area

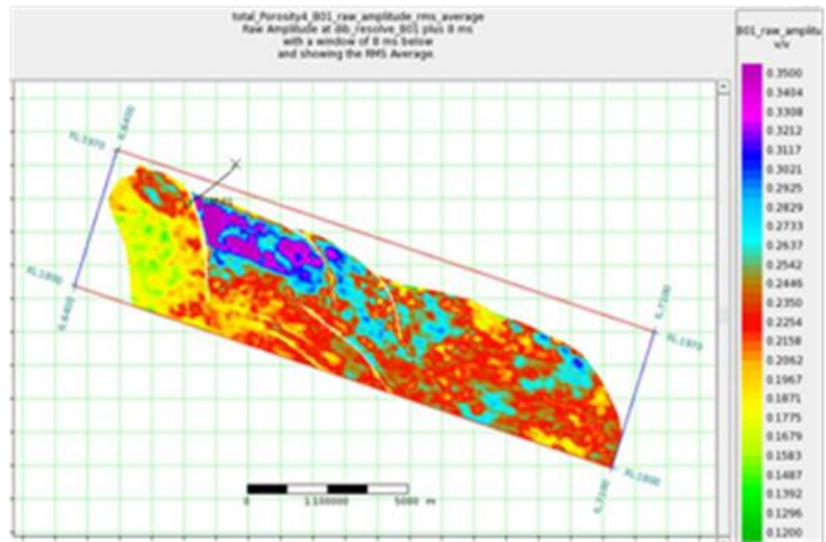

Figure 5: Porosity map showing reservoir ' $\mathrm{X}$ '

\section{CONCLUSION}

We have presented a methodology to predict porosity from 3D seismic inversion data. Seismic amplitude was converted into rock properties - acoustic impedance - through a constrained simultaneous inversion and the inverted properties used to design a multi-regression trend capable of predicting porosity. For this regression case, the overall correlation coefficient between the predicted and actual porosity was about 98\%, considered sufficiently reliable for scientific purposes. This also means that the misfit between predicted and actual porosity falls within a tolerable interval.

This methodology can also be used for a quick evaluation of other reservoir properties such as water saturation. However, it is important to notice that while lateral variability can be adequately captured by the inverted model, it tends to be relatively smooth in the vertical direction due to the low vertical resolution of seismic data in comparison to well log data. As a further step, it would be necessary to test the reservoir performance when the effective porosity model is used for fluid-flow simulation. When more wells become available, porosity prediction should be re-evaluated for more well controls.

\section{ACKNOWLEDGEMENT}

The authors gratefully acknowledge Chevron Nigeria limited for providing data for the study.

\section{REFERENCES}

Calderon, J.E., 2007. Porosity and lithologic estimation using rock physics and multi-attribute transforms in Balcon Field, Colombia. Leading Edge 26 (2), 142150.

Hampson, B., Schuelke, J., Quirein, J., 2001. Use of multiattribute transforms to predict log properties from seismic data. Geophysics 66 (1), 3-46.

Lavergne, M., Willm, C., 1977. Inversion of seismograms and pseudo-velocity logs. Geophysical Prospecting 25, 232-250.

Lefeuvre, F.E., Wrolstad, K.H., Zou, K.S., Smith, L.J., Maret, J.-P., Nyein, U.K., 1995. Sand-shale ratio and sandy reservoir properties estimation from seismic attributes: an integrated study. SEG Expanded Abstracts 95, 108-110.

Leiphart, D. J., Hart , B.S . , 2001. Comparison of linear regression and a probabilistic neural network to predict porosity from 3-D seismic attributes in Lower Brushy Canyon channeled sandstones, southeast New Mexico. Geophysics 66, 1349-1358.

Lindseth, R.O., 1979. Synthetic sonic logs: a process for stratigraphic interpretation. Geophysics 44, 3-26.

Pramanik, A.G., Singh, V., Vig, R., Srivastava, K., Tiwary, D.N., 2004. Estimation of effective porosity using geostatistics and multi-attribute transforms: a case study. Geophysics 69, 352-372. 
Am. J. Sci. Ind. Res., 2013, 4(1): 31-35

Rijks, E. J. K., and Jauffred, J. C. E. M., 1991, Attribute extraction: An important application in any detailed 3-D interpretation study: The Leading Edge, 10, 11-19.

Robinson, G., 2001. Stochastic seismic inversion applied to reservoir characterization. CSEG Recorder 26 (1), 3840.

Russell, B.H., 1988. Introduction to Seismic Inversion Methods. Society of Exploration Geophysicists, Tulsa, OK 86pp.

Russell, B.H., 2004. The application of multivariate statistics and neural networks to the prediction of reservoir parameters using seismic attributes. Ph.D. Disserta-tion. University of Calgary, Alberta. 392pp.

Sancevero, S.S., Remacre, A.Z., Portugal, R.S., Mundim, E.C., 2005. Comparing deterministic and tochastic seismic inversion for thin-bed reservoir characterization in a turbidite synthetic reference model of Campos Basin, Brazil. Leading Edge 24 (11), 10941179.

Soubotcheva, N., 2006. Reservoir Property Prediction from Well-logs, VSP and Multicomponent Seismic Data: Pikes Peak Heavy Oilfield. Saskatchewan. M.Sc. Thesis. Department of Geology and Geophysics, University of Calgary, Alberta, $94 \mathrm{pp}$.

Walls, J.D., Taner, M.T., Taylor, G., Smith, M., Carr, M., Derzhi, N., Drummond, J., McGuire, D., Morris, S., Bregar, J., Lakings, J., 2002. Seismic reservoir characterization of a U.S. idcontinent fluvial system using rock physics, poststack seismic attributes, and neural networks. The Leading Edge 21, 428-436. 